\title{
Antiviral Activities of a Medicinal Plant Extract Against Sacbrood Virus in Honeybees
}

\author{
Liping Sun ${ }^{1 \dagger}$, Xueqi Zhang ${ }^{1,2,4,5 \dagger}$, Shufa $\mathrm{Xu}^{1,5}$, Chunsheng Hou ${ }^{1}$, Jin $\mathrm{Xu}^{1,5}$, Dongxiang Zhao ${ }^{2^{*}}$ and \\ Yanping Chen ${ }^{3^{*}}$ (D)
}

\begin{abstract}
Background: Sacbrood is an infectious disease of the honey bee caused by Scbrood virus (SBV) which belongs to the family Iflaviridae and is especially lethal for Asian honeybee Apis cerana. Chinese Sacbrood virus (CSBV) is a geographic strain of SBV. Currently, there is a lack of an effective antiviral agent for controlling CSBV infection in honey bees.

Methods: Here, we explored the antiviral effect of a Chinese medicinal herb Radix isatidis on CSBV infection in A. cerana by inoculating the 3rd instar larvae with purified CSBV and treating the infected bee larvae with $R$. isatidis extract at the same time. The growth, development, and survival of larvae between the control and treatment groups were compared. The CSBV copy number at the 4th instar, 5th instar, and 6th instar larvae was measured by the absolute quantification PCR method.

Results: Bioassays revealed that $R$. isatidis extract significantly inhibited the replication of CSBV, mitigated the impacts of CSBV on larval growth and development, reduced the mortality of CSBV-infected A. cerana larvae, and modulated the expression of immune transcripts in infected bees.

Conclusion: Although the mechanism underlying the inhibition of CSBV replication by the medicine plant will require further investigation, this study demonstrated the antiviral activity of $R$. isatidis extract and provides a potential strategy for controlling SBV infection in honey bees.
\end{abstract}

Keywords: Apis cerana, Chinese sacbrood virus, Herbal medicine, Antiviral agent, Immunity

\section{Introduction}

The Eastern honeybee (Apis cerana) is an important pollinator for crops and wild plants in Southeast Asia [31]. Compared to its close cousin European honeybee Apis mellifera which is the most widely managed crop pollinator worldwide, A. cerana has several advantages over $A$. mellifera, including the resistance to the parasitic mite Varroa destructor which is the most

\footnotetext{
*Correspondence: dongxiangzh@163.com; judy.chen@ars.usda.gov

'Liping Sun and Xueqi Zhang: contributed equally to this work

${ }^{2}$ Institute of Environment and Plant Protection, Chinese Academy of Tropical Agricultural Sciences, Haikou 571101, Hainan, People's Republic of China

${ }^{3}$ USDA-ARS Bee Research Laboratory, Beltsville, MD 20705, USA

Full list of author information is available at the end of the article
}

devastating pest of European honeybees, tolerance to low temperatures, and ability to utilize sporadic nectar sources in mountain and forest regions [14, 15, 30,33]. However, the health of the Asian honeybee is seriously threatened by Sacbrood virus (SBV). SBV or Morator aetatulas, is an infectious virus belonging to the family of Iflaviridae and infects larvae of both European and Asian honeybees. The infected larvae fail to reach the pupal stage and die eventually. SBV was first detected in A. mellifera in the United States in 1913 [41] and has subsequently been reported in all major world regions where beekeeping practices are present $[1,9]$. While SBV disease has been reported to affect about $15 \%$ of $A$. mellifera [27], it causes the most deadly and devastating disease in A. cerana. Historically, the catastrophic outbreak of SBV disease resulted in $95-100 \%$ original author(s) and the source, provide a link to the Creative Commons licence, and indicate if changes were made. The images or other third party material in this article are included in the article's Creative Commons licence, unless indicated otherwise in a credit line to the material. If material is not included in the article's Creative Commons licence and your intended use is not permitted by statutory regulation or exceeds the permitted use, you will need to obtain permission directly from the copyright holder. To view a copy of this licence, visit http://creativecommons.org/licenses/by/4.0/. The Creative Commons Public Domain Dedication waiver (http://creativeco mmons.org/publicdomain/zero/1.0/) applies to the data made available in this article, unless otherwise stated in a credit line to the data. 
mortality of $A$. cerana colonies in Thailand, Korea, China, and India $[2,11,27,32,40]$.

SBV has evolved into multiple strains based on different geographical distribution. Chinese Sacbrood virus (CSBV) is a geographic strain of SBV infecting Chinese honeybee A. cerana [24]. CSBV primarily infects the 2nd to 3rd instar larvae of honeybees [23], resulting in failure to pupate and death, and eventually collapse of the whole colony [5]. CSBV was first found in A. cerana of Guangdong province in 1972 in China, and then spread rapidly to other regions of China and Southeast Asia and has been regarded as a major threat to A. cerana colonies [24].

So far, there still no effective treatment for CSBV infection. While CSBV infection can be partially relieved by replacing the queen or removing the infected combs from the beehives, such strategies are not effective ways to prevent further dissemination of CSBV among honeybees. RNAi has emerged as a potential method for combating viral diseases in honeybees [6]. Zhang et al. [44] reported that CSBV was significantly inhibited when honeybee larvae were fed with dsRNA corresponding to CSBV major capsid protein VP1 and RNAi-based treatment protected bee larvae from CSBV infection under laboratory conditions. However, the use of RNAi in honeybee disease control has been limited due to its high cost [39] and off-target effects [28], highlighting the need to develop new effective treatments for controlling CSBV infection in honeybees.

Over the years, natural products from plants that possess active ingredients and safety characteristics provide a rich source of candidate treatments for bee and hive health and show potential to be effective agents against bee pathogens, including viruses $[29,36]$. Traditional Chinese herbal medicines display remarkable antiviral effects and have been widely used in the prevention and treatment of viral infectious diseases in humans and other animals [20]. We were motivated to explore the antiviral activity of a Chinese herbal medicine Radix isatidis (Banlangen and Daqingye in Chinese) for controlling CSBV infection in honeybees. R. isatidis is a commonly used traditional Chinese medicine famous for its broadspectrum activity against various pathogens including human and avian influenza viruses $[8,43]$. In this study, we provide evidence that $R$. isatidis extract could effectively inhibit the replication of CSBV in A. ceranae larvae, improve the immune response and extend the lifespan of CSBV infection larvae, clearly demonstrating an effective medicine for protecting honeybees from SBV infection.

\section{Materials and Methods}

\section{Ethics Statement}

Studies involved the Asian honeybee (Apis cerana), which is neither an endangered nor a protected species. Observations were made at the Institute of Apicultural Research, Chinese Academy of Agricultural Sciences (IAR-CAAS), Beijing, China. The apiary is the property of the IAR-CAAS and is not privately owned or protected in any way. No specific permits were required for the studies described.

\section{Apis cerana larvae samples}

Honeybee (A. cerana) colonies used in the study were originated from an experimental apiary maintained at the Institute of Apicultural Research, Chinese Academy of Agricultural Sciences, Beijing, China. In order to obtain the 2nd instar larvae, the queen from a health colony was restricted on a comb to lay eggs for 12 hours. After 48 hours, the comb with the 2nd instar larvae was taken out from the colony. The 2nd instar larvae were then transferred into 24-well plates individually. The 24-well plates were put into an incubator that was set at $32 \pm 1{ }^{\circ} \mathrm{C}$ and $75 \pm 5 \%$ relative humidity. The larvae were fed with manmade larval food and replaced with new diet each day. Detailed information on larval food used in the study is shown in Table 1. A diagram of the experimental design is shown in Fig. 1, and a thorough description of the experimental procedures is followed in the subsequent sections.

\section{CSBV Purification}

For purification of CSBV, infected larvae with significant disease symptoms were collected from field colonies. The presence of CSBV in infected larvae was confirmed by RT-PCR based on the description of Chen et al. [10]. CSBV-infected larvae $(\mathrm{N}=200)$ were divided into two groups and homogenized in a $5 \mathrm{ml}$ sterile phosphate buffer solution (PBS) separately with a sterile grinder. The homogenized mixture was centrifuged at $8000 \mathrm{rpm}$ at $4{ }^{\circ} \mathrm{C}$ for $30 \mathrm{~min}$. The supernatant was passed through a $0.20 \mu \mathrm{m}$ cell filter to remove

\begin{tabular}{llllll}
\multicolumn{2}{l}{ Table 1} & Composition of food for different instar larvae (W/W \%) \\
\hline $\begin{array}{l}\text { Instar } \\
\text { larvae }\end{array}$ & $\begin{array}{l}\text { Volume } \\
(\mu l)\end{array}$ & Glucose \% & $\begin{array}{l}\text { Fructose } \\
\%\end{array}$ & Yeast \% & Royal jelly \% \\
\hline 2 & 20 & 6 & 6 & 1 & 50 \\
3 & 20 & 7.5 & 7.5 & 1.5 & 50 \\
4 & 30 & 9 & 9 & 2 & 50 \\
5 & 50 & 9 & 9 & 2 & 50 \\
6 & 80 & 9 & 9 & 2 & 50 \\
\hline
\end{tabular}




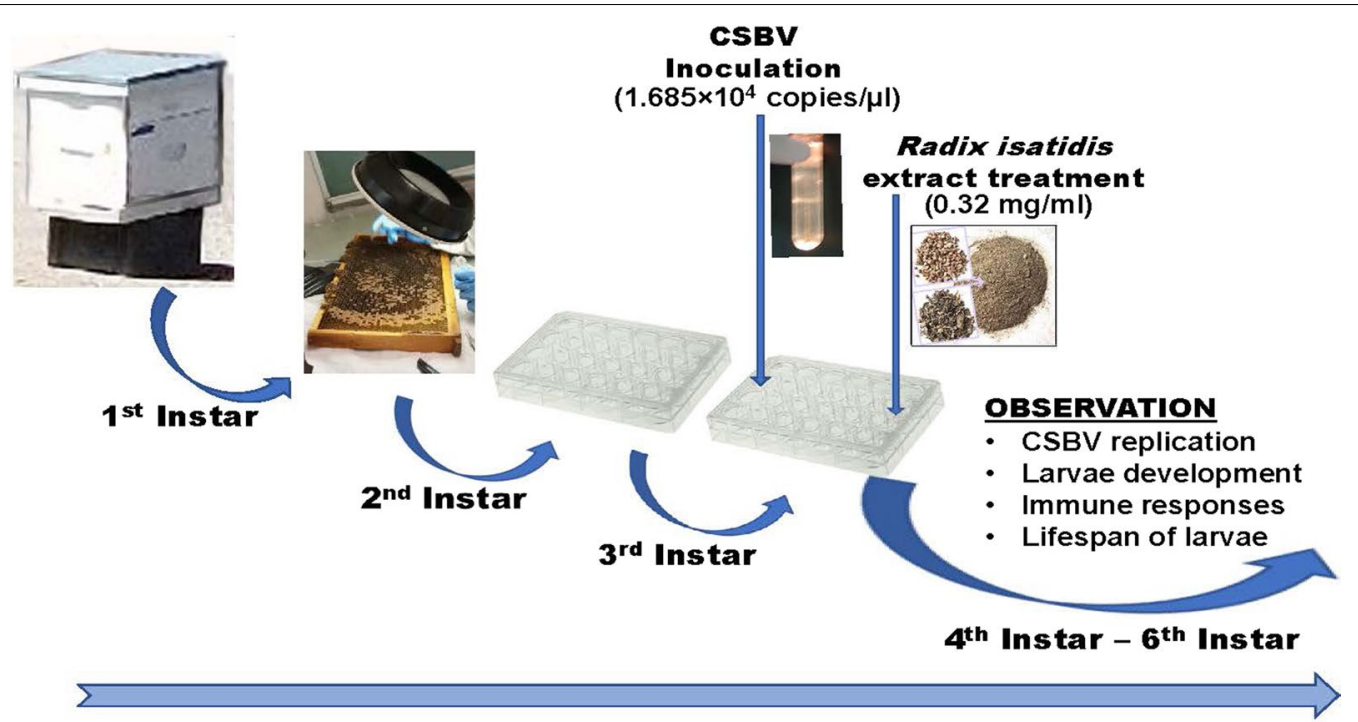

Fig. 1 Graphic representation of the study design

tissue debris and bacteria suspended in the solution. The collected CSBV solution was further purified through $\mathrm{CsCl}$ gradient centrifugations [19]. The $\mathrm{CsCl}$ was removed by dialysis against PBS, and CSBV purification was stored at $-4{ }^{\circ} \mathrm{C}$ for the subsequent inoculation.

\section{RNA Extraction and PCR Amplification}

Total RNA was extracted from CSBV infected larvae using an RNeasy Mini Kit (Adlai, Beijing, China) according to the manufacturer's instructions. The cDNA was synthesized using a reverse transcription kit (Takara, Tokyo, Japan). PCR amplification was performed under the following conditions: initial denaturation at $94{ }^{\circ} \mathrm{C}$ for $5 \mathrm{~min}$ followed by 35 cycles of denaturation at $94{ }^{\circ} \mathrm{C}$ for $30 \mathrm{~s}$, annealing at $58{ }^{\circ} \mathrm{C}$ for $30 \mathrm{~s}$, extension at $72{ }^{\circ} \mathrm{C}$ for $15 \mathrm{~s}$, and a final extension at $72{ }^{\circ} \mathrm{C}$ for $5 \mathrm{~min}$. Then, a 593-bp fragment of the CSBV genome was amplified with primers described by Ma et al. [24]. The size of the PCR products was verified by electrophoresis on $1 \%$ agarose gel in $1 \times$ TAE buffer. The primer specificity of the purified PCR products was confirmed by sequencing analysis.

In addition, PCR assays were performed for RNA extracted from CSBV infected larvae to exclude the presence of the other common bee viruses, including Acute bee paralysis virus (ABPV); Black queen cell virus (BQCV), Chronic bee paralysis virus (CBPV), Deformed wing virus (DWV), Israeli acute paralysis virus (IAPV), and Kashmir bee virus (KBV) following methods described in references [3, 4, 26, 34, 37, 38].

\section{Determination of CSBV Concentration}

The concentration of CSBV purification described above was determined by absolute quantitative Polymerase Chain Reaction (qPCR) using the standard curve method. The forward and reverse primers $\left(5^{\prime}\right.$-ccttggagtttgctatttacg- $3^{\prime}$ and $5^{\prime}$-cctacatccttgggtcag- $3^{\prime}$ ) were used to amplify a 161 bp CSBV fragment. The qPCR was carried out in BIOER LineGene 9600 real-time PCR system $[17,18]$. The qPCR reaction mixture contained a total of $15 \mu$ reaction mixture with $0.3 \mu$ l each of forward and reverse primers, $7.5 \mu \mathrm{l} \mathrm{SYBR}, 1 \mu \mathrm{l}$ cDNA template and $5.9 \mu \mathrm{l}$ water. The PCR reaction began with a single cycle at $95{ }^{\circ} \mathrm{C}$ for $3 \mathrm{~min}$ followed by 40 cycles at $95{ }^{\circ} \mathrm{C}$ for $3 \mathrm{~s}, 60{ }^{\circ} \mathrm{C}$ for $1 \mathrm{~min}$ and $70{ }^{\circ} \mathrm{C}$ for $30 \mathrm{~s}$. The amplified PCR products of CSBV were purified and inserted into a plasmid vector pMD-18 T (Takara, Japan) to generate recombinant plasmid DNA. A standard curve for a dilution series of recombinant CSBV plasmid DNA ranging from 100 to 109 genomic copies was established by plotting $\mathrm{CT}$ values vs. the log of the concentration of genome copies. The solution of CBSV purification was determined to contain $6.74 \times 104 \mathrm{CSBV}$ copies per microliter and defined as initial concentration.

The initial concentration of CSBV was diluted with larval diet at a ratio of 1:1, 1:3 and 1:9 corresponding to $3.37 \times 104,1.685 \times 104$, and $6.74 \times 103$ copies $/ \mu l$, respectively.

\section{CSBV Inoculum}

The 3rd instar (3-day-old) larvae that were reared in 24-well culture plates were divided into three groups by adding $5 \mu \mathrm{l}$ of $3.37 \times 10^{4}, 1.685 \times 10^{4}$ or $6.74 \times 10^{3} \mathrm{CSBV}$ 
copies/ $\mu \mathrm{l}$ into $20 \mu \mathrm{l}$ larval food (Table 1), respectively. At the same time, the larvae in the control group received the regular larval diet (Table1). Each group contained three 24-well culture places $(\mathrm{N}=72$ larvae). The plates were placed into an incubator $\left(32{ }^{\circ} \mathrm{C}\right.$ with humidity of $75 \%)$. According to the larval mortality results, group II inoculated with $1.685 \times 10^{4} \mathrm{CSBV}$ copies/ $\mu$ l larval diet resulted in close to $50 \%$ lethal rate $\left(\mathrm{LD}_{50}\right)$ and therefore the viral concentration of $1.685 \times 10^{4} \mathrm{CSBV}$ copies/ $\mu \mathrm{l}$ was selected for the subsequent evaluation of in vitro antiviral activity of $R$. isatidis extract against CSBV.

\section{Radix isatidis Extract Preparation}

The roots and leaves of Radix isatidis (I. indingtica Fort.) were purchased from Beijing Hongda Kelai Biotechnology Co., Ltd. The equal quantity of extract powder of $R$. isatidis roots and leaves (1:1 ratio) was mixed in highpurity water at a concentration of $22.9 \mathrm{mg} / \mathrm{ml}$, which was used as a stock solution. The stock solution was diluted with the larval diet (Table 1) into the final concentrations of $0.2 \mathrm{mg} / \mathrm{ml}, 0.32 \mathrm{mg} / \mathrm{ml}$, and $0.43 \mathrm{mg} / \mathrm{ml}$ individually. Based on our pilot toxicity evaluation, $15 \mu \mathrm{l}$ of $R$. isatidis extract at a concentration of $0.32 \mathrm{mg} / \mathrm{ml}$ was the most suitable dose to use for treatment as there was no significant difference in survivorship between the control group and the treatment group and was therefore chosen for the subsequent antiviral bioassays.

\section{Bioassay of the CSBV Inhibition with $R$. isatidis Extract}

The 3rd instar (3-day-old) larvae that were reared in 24-well culture plates were divided into three groups: Group I (Negative control $\langle\mathrm{NC}\rangle$, fed with a regular diet without CSBV and $R$. isatidis extract); Group II (CSBV, inoculated with CSBV without $R$. isatidis extract); and Group III- (CSBV\&V R. isatidis extract, inoculated with CSBV and treated with $R$. isatidis extract). Each group contained three 24-well culture places (one plate was used for morphological study, one plate for assessing $R$. isatidis extract antiviral activity, and one plate for monitoring immune responses), making up biological replicates of twenty-four $(\mathrm{N}=24)$. In Group-II, each larva was fed with larval diet containing $5 \mu \mathrm{l}$ of $1.685 \times 10^{4} \mathrm{CSBV}$ copies/ $\mu$ l larval diet while in Group-III, each larva was fed with diet containing both $5 \mu \mathrm{l}$ of $1.685 \times 10^{4} \mathrm{CSBV}$ copies/ $\mu \mathrm{l}$ larval diet and $15 \mu \mathrm{l}$ of $R$. isatidis extract (0.32 $\mathrm{mg} / \mathrm{ml}$ ). The volume of the diet increased each day as larvae instar increased (Table 1) and the larval food was changed every day. For group II and III, the virus-containing food was replaced with regular larval food after 24 hours of inoculating with CSBV. For group III, the $R$. isatidis extract was provided to larvae from the $3^{\text {rd }}$ instar (3-day-old) to the $6^{\text {th }}$ instar (6-day-old). During the feeding process, the food was ensured to be kept on the bottom side of the culture plate to avoid contact with the larvae.

To evaluate the impact of $R$. isatidis extract on the development and survival of the CSBV infected larvae, the larval development in terms of morphology was observed under a stereomicroscope in a rapid manner to avoid the disturbance of the bright light to the developing larvae and recorded daily. The dead larvae were recorded and removed daily. The larval survivor rate between the 4th instar (4-day-old) and the 6th instar (6-day-old) among different groups was recorded and compared.

To assess the antiviral activity of $\mathrm{R}$. isatidis extract against CSBV, five larvae were sampled daily for each group for three days post CSBV inoculation and R. isatidis extract treatment. The CSBV copy number at the 4th instar, 5th instar, and 6th instar larvae was measured by the absolute quantification PCR method as described above and compared among three different experimental groups.

To monitor immune responses of CSBV infected larvae during $R$. isatidis extract treatment, eight larvae were sampled daily for each group for three days post CSBV inoculation and $\mathrm{R}$. isatidis extract treatment. The expression of four genes encoding antimicrobial peptides apidaecin, abaecin, hymenoptaecin and defensin at the 4th instar, 5th instar, and 6th instar larvae was measured and compared among three different experimental groups by relative quantification PCR method $(2-\Delta \Delta C t$ method) [35]. The primers of immune genes and housekeeping gene $\beta$-actin were described by Liu et al. [22] and Chaimanee et al. [7]. The PCR reaction was carried out using a BIOER LineGene 9600 real-time PCR system. The qPCR system contained a total of $20 \mu \mathrm{l}$ with $0.8 \mu \mathrm{l}$ each of primer, $10 \mu \mathrm{l} \mathrm{SYBR}, 1 \mu \mathrm{l}$ cDNA template and $7.4 \mu \mathrm{l}$ water. The PCR reaction began with a single cycle at $95^{\circ} \mathrm{C}$ for $3 \mathrm{~min}, 35$ cycles of $95^{\circ} \mathrm{C}$ for $30 \mathrm{~s}, 60^{\circ} \mathrm{C}$ for $30 \mathrm{~s}, 72^{\circ} \mathrm{C}$ for $30 \mathrm{~s}$. qPCR data analysis was followed. The qPCR data analysis followed the procedure described in Liu et al. [22].

\section{Statistical Analysis}

The standard curve method was employed for the absolute quantification of CSBV. The relative expression level of the antibacterial peptide target gene was calculated by $2^{-\triangle \triangle C T}$ method. The results were expressed as mean \pm standard deviation (SD). The one-way analysis of variance (ANOVA) and Tukey's Honestly Significant Difference (HSD) test were used to compare the difference in the copy number of CSBV, survivor rate, and abundance of immune transcripts among three different groups using SPSS 22.0 (SPSS, Chicago, Illinois, USA). Percentage data (survivor rate) were Arc Sine transformed before 
the statistical analysis. A $p$-value of $\leq 0.05$ was regarded as statistically significant.

\section{Results}

$R$. isatidis extract could reverse the effects of CSBV on larval growth and development

The comparison of the morphology of larvae across three different groups showed that CSBV could severely impact the growth and development of $A$. cerana larvae and that $R$. isatidis extract was able to reverse the negative effects of CSBV on larval growth and development. Of 24 larvae in each experimental group, $100 \%$ of larvae in Group-I displayed normal development, $60.92 \%$ and $39.98 \%$ of larvae in Group-II were arrested at the fourth and fifth instar, respectively, without further development. Meanwhile, $86.15 \%$ of larvae in Group-II showed normal development and only $4.76 \%$ and $12.26 \%$ of larvae were arrested at the fourth and the fifth instar, respectively. A representative larvae morphological development is shown in Fig. 2. In Group-I, healthy larvae were pearly white and curved into a $\mathrm{C}$-shape. The size of larvae increased significantly during each successive number of larval instars starting at the 4th instar larval stage and the body color of larvae turned into light yellow once they reached to the 6th instar. Compared to larvae in Group-I, CSBV infected larvae in Group-II showed a severe delay in development. The size of the CSBV infected larvae in

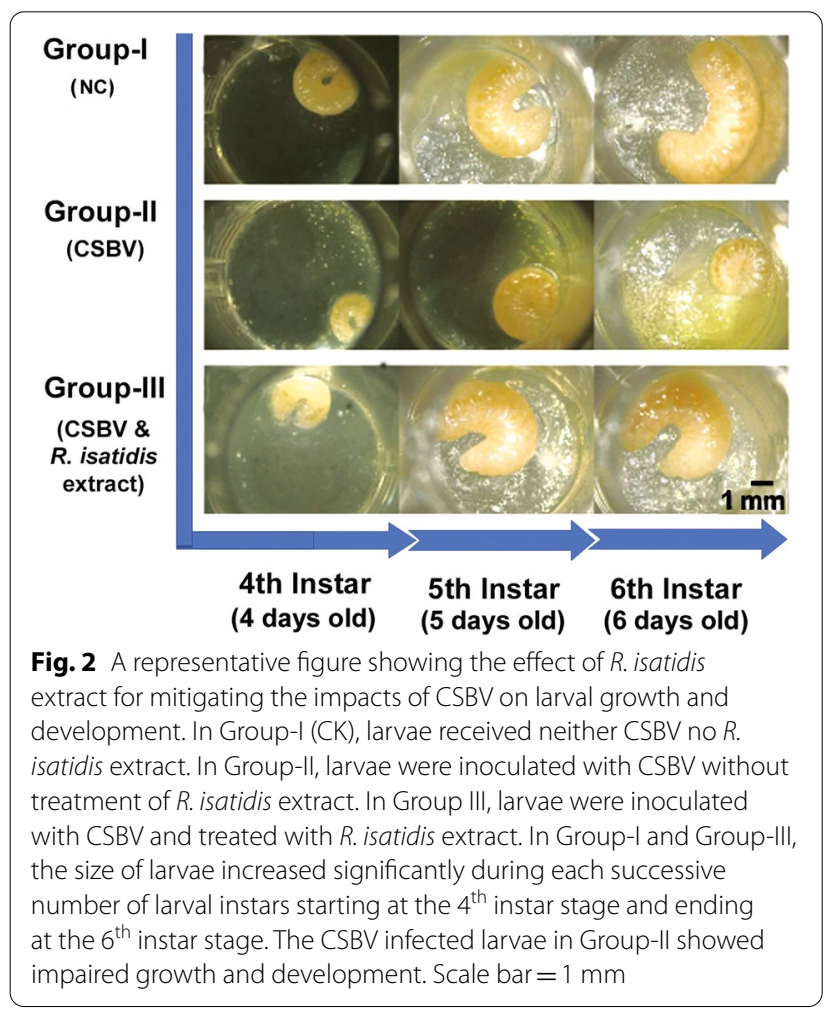

Group-II was significantly smaller than that of larvae in Group-I. In addition, the color of CSBV infected larvae became dark brown, and more food is left on the bottom of the plate. Meanwhile, the CSBV infected larvae treated with $R$. isatidis extract in Group-III displayed a similar growth and development as larvae in Group-I. There was no significant difference in overall larval morphology and development between Group-I and Group-III (Fig. 2).

\section{Radix isatidis Extract Could Inhibit the Replication of CSBV}

There was a statistically significant difference in the copy number of CSBV between Group II and Group III at different instar (4th instar: $p<0.01$, 5th instar: $p<0.01$, and 6th instar: $p<0.01$, t-test). While there was no detectable level of CSBV in Group-I (N.C.), the copy number of CSBV in Group-II was $1.21 \times 10^{5}$ copies $/ \mu$ l, $4.71 \times 10^{4}$ copies $/ \mu \mathrm{l}$, and $2.328 \times 10^{4}$ copies $/ \mu \mathrm{l}$ in the 4 -day-old, 5-day-old, and 6-day-old larvae, respectively. Compared to Group-II, a substantial decrease in CSBV copy number was observed in Group-III $24 \mathrm{~h}$ after $R$. isatidis extract treatment. The CSBV copy number in Group-III was found to continue to decrease steadily in response to the treatment of $R$. isatidis extract for $72 \mathrm{~h}$. The CSBV copy number in Group-III larvae was $1.35 \times 10^{3}$ copies $/ \mu \mathrm{l}$, $1.91 \times 10^{2} \mathrm{copies} / \mu \mathrm{l}$ and $2.32 \times 10^{2} \mathrm{copies} / \mu \mathrm{l}$ in the 4 -dayold, 5-day-old, and 6-day-old larvae, respectively, clearly indicating the inhibitory activity of $R$. isatidis extract against CSBV in vivo (Fig. 3).

\section{Radix isatidis Extract Could Extend the Lifespan of CSBV-Infected Larvae}

As shown in Fig. 4a, b, CSBV infection has a significant impact on larval survivorship. Larvae in Group-II displayed the highest mortality during the period of observation and at each instar stage among three groups. While the survival rate at Group-I was $98.61 \%$, 97.16\% and $98.61 \%$ for 4-day-old, 5-day-old, and 6-day-old larvae, respectively, the survival rate in Group-II was $75 \%$, $77.3 \%$, and $79.08 \%$ for 4-day-old, 5-day-old, and 6-dayold larvae, respectively. However, the survivorship of CSBV-infected bees was significantly improved by applying $R$. isatidis extract. The survival rate in Group-III was $97.22 \%, 100 \%$, and $92.93 \%$ for 4-day-old, 5-day-old, and 6-day-old larvae, respectively. The overall survivorship during a period of observation was $98.61 \%, 43.05 \%$, and 93.05\% for Group-I, Group-II, and Group-III, respectively, clearly indicating that $R$. isatidis extract could result in a significantly improved survival of CSBV infected larvae.

One-way ANOVA and Tukey's Honestly Significant Difference tests of the arcsine transformation of percentage data showed there was statistically significant difference in survivor rates among different experiment group. 


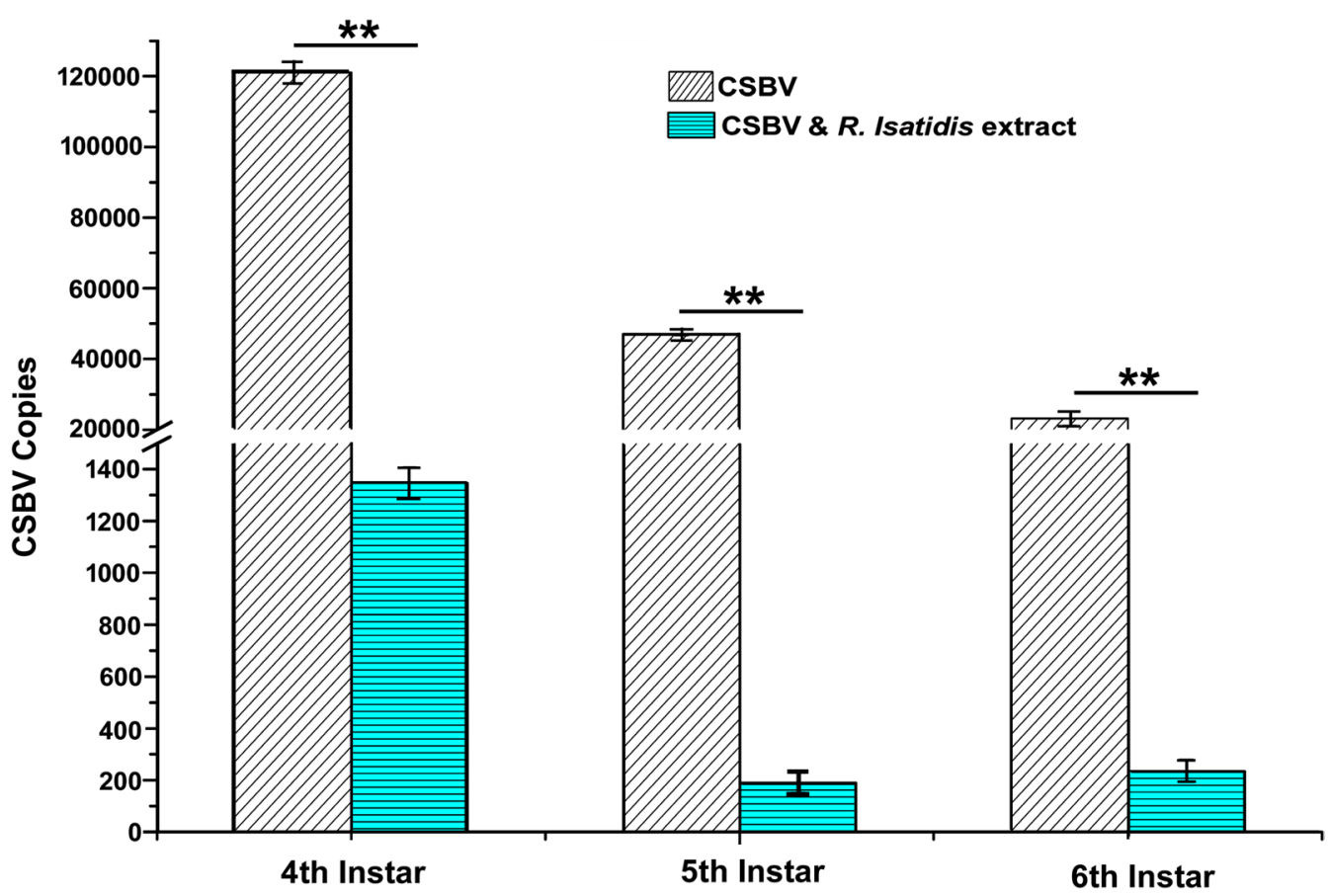

Fig. 3 Inhibitory effects of $R$. isatidis extract on CSBV replication. In Group-II, larvae were inoculated with CSBV without treatment of $R$. isatidis extract. In Group III, larvae were inoculated with CSBV and treated with R. isatidis extract. Absolute RT-qPCR measurement of CSBV gene copy number was conducted on the $4^{\text {th }}$ instar, $5^{\text {th }}$ instar, and $6^{\text {th }}$ instar larvae $24 \mathrm{~h}$ post CSBV inoculation for both Group-II and Group-III. Two asterisks (**) above denote a statistically significant difference between the two groups ( $P \leq 0.01$, Student's t-test)

The survivor rate in Group II was statistically significantly lower than Group I. The R. isatidis extract treatment could improve the survivor of CSBV infected larvae as there was no statistically significant difference in survivor rate between the Group I and Group II at three different instar larvae (4th instar: $P=0.008, \mathrm{~F}(2,6)=11.704$, G-I vs. G-II $P=0.012$, G-II vs. G-III $P=0.016$, G-I vs. G-III $P=0.959 ; 5$ th instar: $P=0.001, F(2,6)=25.144$, G-I vs. G-II $P=0.006$, G-II vs. G- III $P=0.001, \mathrm{G}-\mathrm{I}$ vs. G-III $P=0.210$; 6th instar: $P=0.017, \mathrm{~F}(2,6)=8.759$, G-I vs. G-II $P=0.014$, G-II vs. G-III $P=0.098$, G-I vs. G-III $P=0.308$; Average: $P=0.003, \mathrm{~F}(2,6)=18.449$, G-I vs. G-II $P=0.005$, G-II vs. G-III $P=0.004$, G-I vs. G-III $P=0.995))($ Fig. 4a, b).

\section{Relative Expression of Four Antimicrobial Peptides}

Relatve gene expression analysis showed that the expression levels of genes encoding antimicrobial peptides including apidaecin, abaecin, hymenoptaecin and defensin was activated in CSBV infected larvae (Group II) at different larval instar stages. One-way ANOVA and Tukey's Honestly Significant Difference tests showed the expression levels of four immune genes were significantly higher in Group-II than that in Group-I (Abaecin-4th instar: $P=0.000, F(2,6)=62.091$, G-I vs.
G-II $P=0.0001$, 5th instar: $P=0.000, F(2,7)=104.196$, G-I vs. G-II $P=0.0001$, and 6th instar: $P=0.000$, $\mathrm{F}(2,6)=208.223$, G-I vs. G-II $P=0.000$; Apidaecin-4th instar: $P=0.000, \mathrm{~F}(2,6)=43.127$, G-I vs. G-II $P=0.0001$, 5th instar: $P=0.000, F(2,6)=1972.049$, G-I vs. G-II $\mathrm{P}=0.0001$, 6th instar: $P=0.000, \mathrm{~F}(2,6)=64.515$, G-I vs. G-II $P=0.0001$; Hymenoptaecin-4th instar: $P=0.000$, $\mathrm{F}(2,6)=709.958$, G-I vs. G-II $P=0.0001,5$ th instar: $P=0.0001, \mathrm{~F}(2,7)=565.060$, G-I vs. G-II $P=0.000$, 6th instar: $P=0.000, \mathrm{~F}(2,6)=687.439$, G-I vs. G-II $P=0.0001$; and Defensin-4th instar: $P=0.039, \mathrm{~F}(2,6)=5.851$, G-I vs. G-II $P=0.047$, 5th instar: $P=0.000, \mathrm{~F}(2,6)=56.606$, G-I vs. G-II $P=0.000$, 6th instar: $P=0.000, F(2,7)=421.010$, G-I vs. G-II $P=0.0001$ ) (Fig. 5).

$R$. isatidis extract inhibited CSBV replication, which in turn led to the reduction in the intensity of the immune response in honey bee larvae. The relative expression levels of genes encoding apidaecin, abaecin, hymenoptaecin and defensin in Group III larvae was significantly lower than that in Group II, end an immune response. However, the immune response didn't disappear completely after the treatment of $R$. isatidis extract as there was still significant difference in the relative expression levels of genes encoding apidaecin, abaecin, hymenoptaecin and defensin between Group I and Group III (Abaecin-4th 

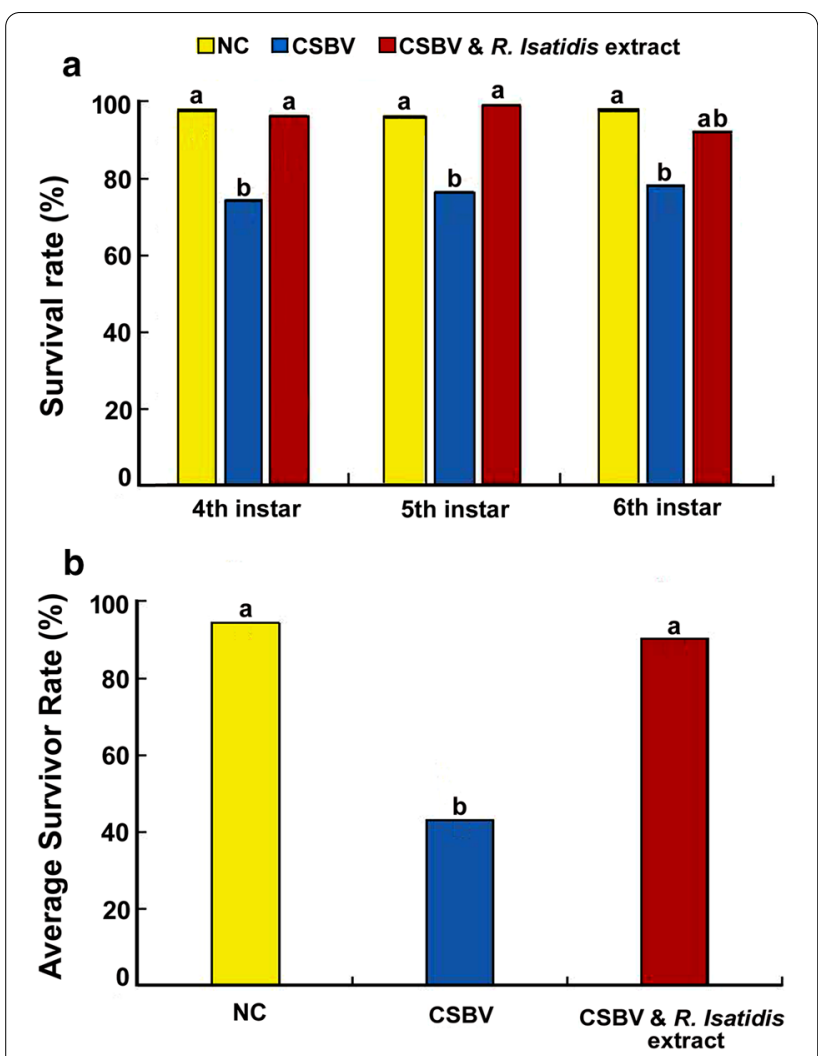

Fig. 4 The effects of $R$. isatidis extract on extending the lifespan of CSBV-infected larvae. a The daily survival rate of different groups. $\mathbf{b}$ The overall survivor rate during a period of observation of different groups. In Group-I (CK), larvae received neither CSBV no R. isatidis extract. In Group-II, larvae were inoculated with CSBV without treatment of $R$. isatidis extract. In Group III, larvae were inoculated with CSBV and treated with $R$. isatidis extract. The different lower case letters above bars indicate the statistically significant difference among different groups ( $P \leq 0.05$, ANOVA and Tukey's tests)

instar: G-II vs. G-III $P=0.001$, G-I vs. G-III $P=0.040$, 5th instar: G-II vs. G-III $P=0.000$, G-I vs. G-III $P=0.032$, 6th instar: G-II vs. G-III $P=0.000$, G-I vs. G-III $P=0.001$; Apidaecin-4th instar: G-II vs. G-III $P=0.001$, G-I vs. G-III $P=0.802$, 5th instar: G-II vs. G-III $P=0.000$, G-I vs. G- III $P=0.000$, 6th instar: G-II vs. G-III $P=0.000$, G-I vs. G-III $P=0.228$; Hymenoptaecin-4th instar: G-II vs. G-III $P=0.0001$, G-I vs. G-III $P=0.0001$, 5th instar: G-II vs. G-III $P=0.0001$, G-I vs. G-III $P=0.0001,6$ th instar: G-II vs. G-I $P=0.0001$, G-I vs. G-III $P=0.002$; Defensin-4th instar: G-II vs. G-III $P=0.931, \mathrm{G}-\mathrm{I}$ vs. G-III $P=0.073,5$ th instar: G-II vs. G-III $P=0.001, \mathrm{G}-\mathrm{I}$ vs. G-III $P=0.042$, 6th instar: G-II vs. G-III $P=0.0001$, G-I vs. G-III $P=0.0001$ ) (Fig. 5).

Except for defensin, the other three immune genes had their peak of expression $24 \mathrm{~h}$ post CSBV infection and then declined thereafter. This inducible innate immune response to CSBV infection subsided with the treatment of $R$. isatidis extract. Except for the expression of defen$\sin$ at the $4^{\text {th }}$ instar larvae, the expression levels of apidaecin, abaecin, and hymenoptaecin in Group-III expression were significantly lower than that in Group-II. The fold change in the gene expression levels between larvae in Group-II and larvae in Group-III was more than ten folds (Fig. 5).

\section{Discussion}

Due to natural products' attractive properties such as safe, non-toxic, and biodegradable, they have been a rich source of medicines against various diseases including viral diseases. In this report, we provided evidence that the extract of a Chinese medicinal plant $\mathrm{R}$. isatidis could inhibit honey bee SBV replication, modulate honey bees' immune responses, and restore honey bees' viability from SBV disease challenge, adding a new dimension to the role of the herb medicines in disease treatment and management.

Chinese sacbrood virus (CSBV) is the leading cause of A. cerana colony mortality, necessitating effective treatments that are safe, efficacious, and cost-effective. Herbal products have been used in traditional Chinese medicine for centuries. Previous studies have shown that Chinese herb medicines have unique roles in blocking viral replication or exerting direct or indirect antiviral effects [20]. $\mathrm{R}$. isatidis (Ban-Lan-Gen) is a traditional Chinese herbal medicine that has been used for the prevention and treatment against a wide range of diseases, including viral diseases (reviewed in Zhou 2012). Several biologically active compounds have been isolated from $\mathrm{R}$. isatidis and shown to have antioxidant and antiviral properties. For example, indirubin, a main active ingredient of $R$. isatidis, was reported to have potent antiviral and anti-inflammatory effects via inhibition of RANTES, is a member of a large family of cytokines that play a regulatory role in inflammatory processes [25, 27]. In addition, $\mathrm{R}$. isatidis polysaccharides were found to inhibit the replication of human and avian influenza viruses [21]. Furthermore, Clemasta$\operatorname{nin} B$, and epigoitrin which are major phenylpropanoid compounds and abundant alkaloid in R. Isatidis, respectively, could effectively inhibit human and avian influenza viruses by blocking virus attachment and inhibiting virus multiplication [42, 43]. In our study, the dosage of 48 ug $R$. isatidis extract per larva each day $(15 \mu \mathrm{L}$ of $0.32 \mathrm{mg} /$ $\mathrm{mL} R$. isatidis extract) did not lead to toxic effects, indicating that $\mathrm{R}$. isatidis is of safe and non-toxic for honey bees. Our results that CSBV load of the Group-III treated with R. isatidis extract was significantly lower than the virus control Group-II and that development and survival rate of Group-III was significantly higher than that of Group II demonstrated the significant antiviral activity 


\section{DNC ICSBV ZCSBV \& R. Isatidia Extract}
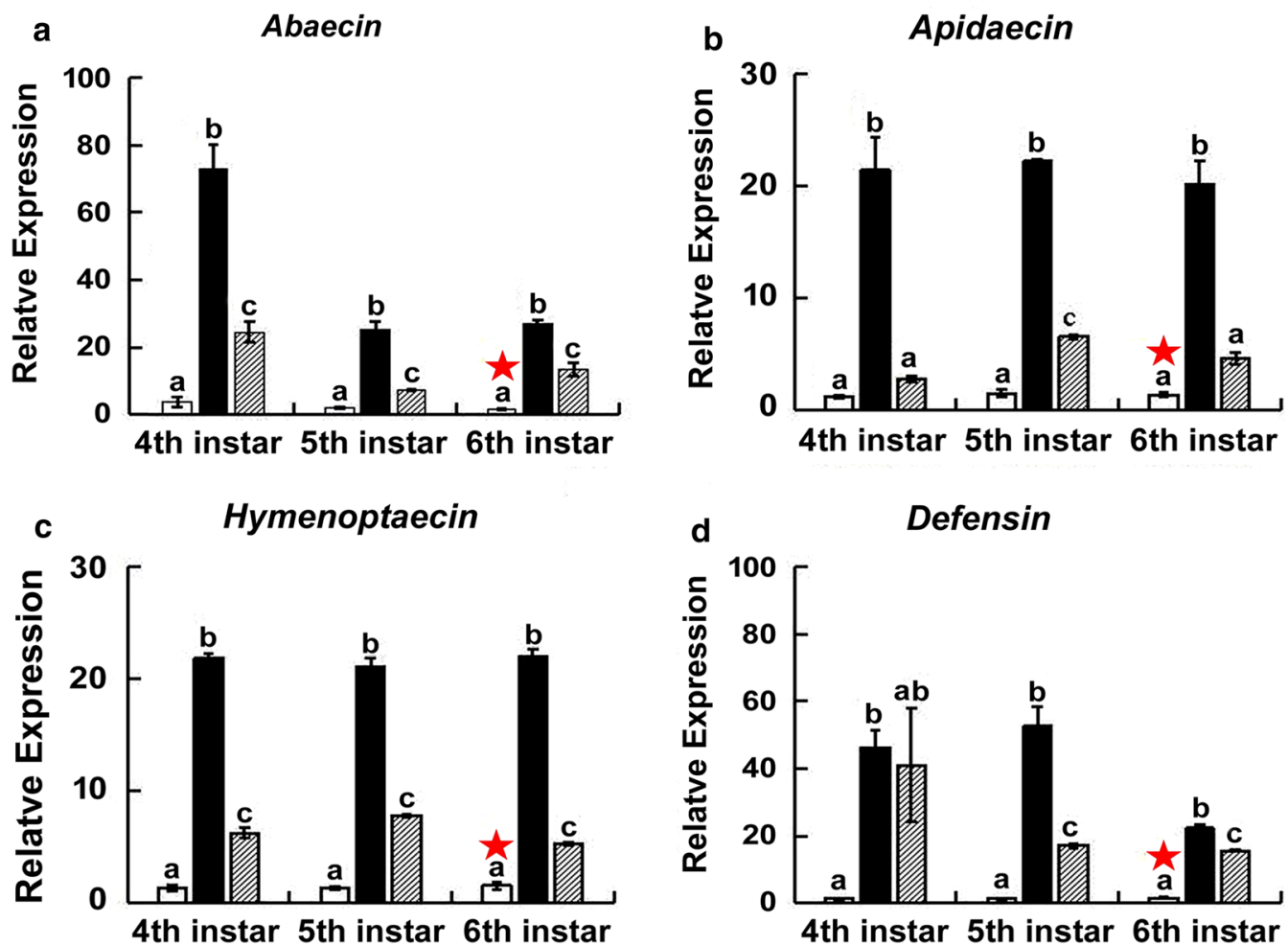

Fig. 5 Relative changes of genes encoding antimicrobial peptides abaecin (a) apidaecin (b), hymenoptaecin (c) and defensin (d). For each gene, the relative expression was expressed as an $\mathrm{n}$-fold difference relative to the calibrator (marked by a star) by $2^{-\Delta \Delta C t}$ method. In Group-I (CK), larvae received neither CSBV no R. isatidis extract. In Group-II, larvae were inoculated with CSBV without treatment of R. isatidis extract. In Group III, larvae were inoculated with CSBV and treated with $R$. isatidis extract. The different lower case letters above bars indicate the statistically significant difference among different groups ( $P \leq 0.05$, ANOVA and Tukey's tests)

of R. isatidis against lethal infections of CSBV. The results encourage future evaluation of $\mathrm{R}$. isatidis extract as an antiviral agent for the treatment of other viruses in honey bees. Future studies are also needed to identify, isolate, and characterize specific active ingredients of $R$. isatidis that are responsible for inhibiting CSBV.

Innate immunity is the first line of defense against invading microorganisms in insects and consists of cellular and humoral responses [16]. Humoral response refers to the activation of downstream intracellular signaling molecules by germline-encoded pattern recognition receptors that recognize pathogen-associated molecular patterns and the production of soluble effector molecules, antimicrobial peptides (AMPs), in response to invaders. Several AMPs, including apidaecin, hymenoptera, abaecin and defensin which are regulated by two intracellular signaling pathways Toll and Imd/JNK have been described in the honey bee $[12,13]$. During viral infection, the rapid production of AMPs as a part of the host defense response is necessary to promote virus clearance and to prevent virus spread within the host. Our study showed that CSBV infection induced the rapid elevation of expression levels of the AMPs apidaecin, hymenoptera, abaecin and defensin, reflecting that honey bee host's innate immunity acted quickly to mount a first line of defense. The significant reduction in virus titer after the treatment with $\mathrm{R}$. isatidis extract was accomplished with substantially subsided host immune responses as shown that the expression levels of four AMPs in Group-III expression were over ten-fold lower than that in Group-II. This result clearly demonstrated the immunomodulatory roles of the herbal extract. However, more research is needed to better understand the mechanism of $R$. isatidis in the protection against CSBV replication and the modulation of the innate immune response in the future.

\section{Conclusion}

In conclusion, our findings clearly demonstrate that $R$. isatidis can be a significant antiviral therapeutic agent to inhibit CSBV infection in honey bees. The results obtained from this study may serve as a basis for further exploration 
of herbal medicinal plants or substances derived from them for the discovery and production of novel antiviral drugs for disease treatment in honey bees.

\begin{abstract}
Abbreviations
SBV: Sacbrood virus; CSBV: Chinese Sacbrood virus; IAR-CAAS: Institute of Apicultural Research, Chinese Academy of Agricultural Sciences; PBS: Phosphate buffer solution; ABPV: Acute bee paralysis virus; BQCV: Black queen cell virus; CBPV: Chronic bee paralysis virus; DWV: Deformed wing virus; IAPV: Israeli acute paralysis virus; KBV: Kashmir bee virus; qPCR: Quantitative Polymerase Chain Reaction; SD: Standard deviation; ANOVA: Analysis of variance; HSD: Honestly Significant Difference; NC: Negative control; AMPs: Antimicrobial peptides.
\end{abstract}

\section{Acknowledgements}

We thank Weipeng Kang, and Zhonghua Zhao (Institute of Apicultural Research, Chinese Academy of Agricultural Sciences) for collecting the honeybee samples. We thank Yanchun Deng (Institute of Apicultural Research, Chinese Academy of Agricultural Sciences) for providing the primers of CSBV. We thank the Core Facility and Technical Support of Apicultural Research, Chinese Academy of Agricultural Sciences, for their technical assistance in QPCR (Jilian Li, Liuhao Wang, Kai Li). We think Alex Sadzewicz for proof reading of the final version of the manuscript.

\section{Authors' contributions}

$S L, D Z$, and YPC conceptualized the study, XZ, SL, XS, and DZ designed the experiments, SL, SX and DZ provided resources, XZ, JX, CH performed the experiments, XZ and JX analyzed and validated data, XZ, SL, YPC, prepared manuscript. All authors read and approved the final manuscript.

\section{Funding}

This research was funded by China Agriculture Research System (CARS-44). Yanping Chen was supported in part by the U.S. Department of Agriculture (USDA) - Animal and Plant Health Inspection Service (APHIS) fund (20-8130-0747-IA).

\section{Availability of data and materials}

All data supporting the conclusions of this article are included in this published article.

\section{Declarations}

\section{Ethics approval and consent to participate}

Not applicable.

\section{Consent for publications \\ Not applicable.}

\section{Competing interests}

The authors declare that they have no competing interests.

\section{Author details}

${ }^{1}$ Institute of Apicultural Research, Chinese Academy of Agricultural Sciences, Beijing 100093, People's Republic of China. ${ }^{2}$ Institute of Environment and Plant Protection, Chinese Academy of Tropical Agricultural Sciences, Haikou 571101, Hainan, People's Republic of China. ${ }^{3}$ USDA-ARS Bee Research Laboratory, Beltsville, MD 20705, USA. ${ }^{4}$ Apiculture Institute of Jiangxi Province, Nanchang 330052, People's Republic of China. ${ }^{5}$ Key Laboratory of Pollinating Insect Biology, Ministry of Agriculture, Beijing 100093, People's Republic of China.

Received: 26 October 2020 Accepted: 8 April 2021

Published online: 21 April 2021

\section{References}

1. Allen M, Ball B. The incidence and world distribution of honey bee viruses. Bee World. 1996;77:141-62.

2. Bailey L, Carpenter JM, Woods RD. A strain of sacbrood virus from Apis cerana. J Invertebrate Pathol. 1982;39:264-5.

3. Bakonyi T, Farkas R, Szendroi A, Kovács MD, Rusvai M. Detection of acute bee paralysis virus by RT-PCR in honey bee and Varroa destructor field samples: rapid screening of representative Hungarian apiaries. Apidologie. 2002;33:63-74.

4. Benjeddou M, Leat N, Allsopp M, Davison S. Detection of acute bee paralysis virus and black queen cell virus from honeybees by reverse transcriptase PCR. Appl Environ Microbiol. 2001;67:2384-7.

5. Berényi O, Bakony T, Derakhshifar I, Köglberger H, Nowotny N. Occurrence of six honeybee viruses in diseased Austrian apiaries. Appl Environ Microbiol. 2006;72:2414-20.

6. Brutscher LM, Flenniken ML. RNAi and antiviral defense in the honey bee J Immunol Res. 2015;2015:941897.

7. Chaimanee V, Chantawannakul P, Chen YP, Evans JD, Pettis JS. Differential expression of immune genes of adult honey bee (Apis mellifera) after inoculated by Nosema ceranae. J Insect Physiol. 2012;58:1090-5.

8. Chen K, Dou Y, Chen Z, Tian JZ. Advance of Radix Isatidis pharmacological action and active substances. Chin J Exp Tradit Med Formlae. 2011;18:275-8.

9. Chen YP, Siede R. Honey bee viruses. Adv Virus Res. 2007;70:33-80.

10. Chen YP, Zhao Y, Hammond J, Hsu H, Evans JD, Feldlaufer MF. Multiple virus infections in the honey bee and genome divergence of honey bee viruses. J Invertebr Pathol. 2004;87:84-93.

11. Choe SE, Nguyen LT, Noh JH, Kweon CH, Reddy KE, Koh HB, Chang KY, Kang SW. Analysis of the complete genome sequence of two Korean sacbrood viruses in the honey bee, Apis mellifera. Virology. 2012;432:155-61.

12. Danihlík J, Aronstein K, Petřivalský M. Antimicrobial peptides: a key component of honey bee innate immunity. J Apic Res. 2016;54:123-36.

13. Evans JD, Aronstein $K$, Chen YP, Hetru C, Imler JL, Jiang H, Kanost M, Thompson GJ, Zou Z, Hultmark D. Immune pathways and defence mechanisms in honey bees Apis mellifera. Insect Mol Biol. 2006;15:645-56.

14. Fries I, Wei H, Shi W, Chen SJ. Grooming behavior and damaged mites (Varroa jacobsoni) in Apis cerana cerana and Apis mellifera ligustica. Apidologie. 1996;27:3-11.

15. Gong YF, Zhang QK. Taxonomy and evolutionary of honey bee. Fuzhou: Fujian Science and Technology Press; 2000. p. 21

16. Hoffmann JA. Innate immunity of insects. Curr Opin Immunol. 1995;7:4-10.

17. Hong KM, Najjar H, Hawley M, Press RD. Quantitative real-time PCR with automated sample preparation for diagnosis and monitoring of cytomegalovirus infection in bone marrow transplant patients. Clin Chem. 2004;50:846-56.

18. Hu Z-G, Chen K-P, Yao Q, Gao G-T, Xu J-P, Chen H-Q. Cloning and characterization of Bombyx mori PP-BP, a gene induced by viral infection. Acta Genet Sin. 2006;33:975-83.

19. Li JL, Cornman RS, Evans JD, Pettis JS, Zhao Y, Murphy C, Peng WJ, Wu J, Boncristiani HF, Zhou L, Chen YP. Systemic spread and propagation of a plant pathogenic virus in European honey bees Apis mellifera. $\mathrm{mBIO}$. 2014:5:e00898-e913.

20. LiT, Peng T. Traditional Chinese herbal medicine as a source of molecules with antiviral activity. Antivir Res. 2013;97:1-9.

21. Li Z, Li L, Zhou H, Zeng L, Chen T, Chen Q, Zhou B, Wang Y, Chen Q, Hu P, Yang Z. Radix isatidis polysaccharides inhibit influenza a virus and influenza a virus-induced inflammation via suppression of host TLR3 signaling in vitro. Molecules (Basel, Switzerland). 2017;22(1):116.

22. Liu S, Wang LH, Guo J, Tang YJ, Chen YP, Wu J, Li JL. Chinese sacbrood virus infection in Asian honey bees (Apis cerana cerana) and host immune responses to the virus infection. J Invertebr Pathol. 2017;150:63-9.

23. Ma M. New insights of Sacbrood virus. Virol Sin. 2014;29:410-3.

24. Ma Mingxiao M, Ming L, Jian C, Song Y, Shude W, Pengfei L. Molecular and biological characterization of Chinese sacbrood virus LN isolate. Comp Funct Genomics. 2011;2011:409386.

25. Mak NK, Leung CY, Wei XY, Shen XL, Wong RN, Leung KN, Fung MC. Inhibition of rantes expression by indirubin in influenza virus-infected human bronchial epithelial cells. Biochem Pharmacol. 2004;67:167-74.

26. Maori E, Lavi S, Mozes-Koch R, Gantman Y, Peretz Y, Edelbaum O, Tanne E, Sela I. Isolation and characterization of Israeli acute paralysis virus, a 
dicistrovirus affecting honeybees in Israel: evidence for diversity due to intra- and inter-species recombination. J Gen Virol. 2007;88:3428-38.

27. Rao KM, Katna S, Rana BS, Rana R. Thai sacbrood and sacbrood viruses versus European foulbrood of hive bees in India - a review. J Apicult Res. 2015;54:192-9.

28. Nunes F, Aleixo AC, Barchuk AR, Bomtorin AD. Non-target effects of green fluorescent protein (GFP)-derived double-stranded RNA (dsRNA-GFP) Used in honey bee RNA interference (RNAi) assays. Insects. 2013:4:90-103.

29. Palmer-Young EC, Tozkar CÖ, Schwarz RS, Chen Y, Irwin RE, Adler LS, Evans JD. Nectar and pollen phytochemicals stimulate honey bee (Hymenoptera: Apidae) immunity to viral infection. J Econ Entomol. 2017;110:1959-72.

30. Peng YS, Fang Y, Xu S, Ge L. The resistance mechanism of the Asian honey bee, Apis cerana Fabr., to an ectoparasitic mite, Varroa jacobsoni Oudemans. J. Invertebr. Pathol. 1987; 49:54-60.

31. Potts SG, Biesmeijer JC, Kremen C, Neumann P, Schweiger O, Kunin WE. Global pollinator declines: trendsim, pacts and drivers. Trends Ecol Evol. 2010;25:345-53.

32. Rana BS, Garg ID, Khurana SP, Verma LR, Agrawal HO. Thai sacbrood virus of honeybees (Apis cerana indica F) in North-west Himalayas. Indian J Virol. 1986;2:127-31.

33. Rath W. Co-adaptation of Apis cerana Fabr. and Varroa jacobsoni Oud. Apidologie. 1999; 30:97-110.

34. Ribiere M, Triboulot C, Mathieu L, Mathieu L, Aurieres C, Faucon JP, Pein M. Molecular diagnostic of chronic bee paralysis virus infection. Apidologie. 2002:33:339-51

35. Schmittgen TD, Livak KJ. Analyzing real-time PCR data by the comparative C(T) method. Nat Protoc. 2008;3:1101-8.

36. Stamets PE, Naeger NL, Evans JD, Han JO, Hopkins BK, Lopez D, Moershel HM, Nally R, Sumerlin D, Taylor AW, Carris LM, Sheppard WS. Extracts of polypore mushroom mycelia reduce viruses in honey bees. Sci Rep. 2018;8:13936.

37. Stoltz D, Shen XR, Boggis C, Gary S. Molecular diagnosis of Kashmir bee virus infection. J Apic Res. 1995;34:153-60.

38. Tentcheva D, Gauthier L, Jouve S, Rochelle LC, Dainat B, Cousserans F, Colin ME, Brenda V, Ball BV, Bergoin M. Polymerasechain reaction detection of deformed wing virus (DWV) in Apis mellifera and Varroa destructor. Apidologie. 2004;35:431-9.

39. Vélez AM, Jurzenski J, Matz N, Zhou X, Wang H, Ellis M, Siegfried BD. Developing an in vivo toxicity assay for RNAi risk assessment in honey bees Apis mellifera L.. Chemosphere. 2016;144:1083-90.

40. Verma LR, Rana BS, Verma S. Observations on Apis cerana colonies surviving from Thai sacbrood virus infestation. Apidologie. 1990;21:169-74.

41. White GF. Sacbrood, a Disease of Bees. US Department of Agriculture, Bureau of Entomology; Washington, DC; 1913.

42. Xiao P, Ye W, Chen J, Li X. Antiviral activities against influenza virus (FM1) of bioactive fractions and representative compounds extracted from Banlangen (Radix Isatidis). J Tradit Chin Med. 2016;36:369-76.

43. Yang Z, Wang Y, Zheng Z, Zhao S, Zhao J, Lin Q, Li C, Zhu Q, Zhong N. Antiviral activity of Isatis indigotica root-derived clemastanin $B$ against human and avian influenza A and B viruses in vitro. Int J Mol Med. 2013;31:867-73.

44. Zhang J, Zhang Y, Han R. The high-throughput production of dsRNA against sacbrood virus for use in the honey bee Apis cerana (Hymenoptera: Apidae). Virus Genes. 2016;52:698-705.

\section{Publisher's Note}

Springer Nature remains neutral with regard to jurisdictional claims in published maps and institutional affiliations.
Ready to submit your research? Choose BMC and benefit from:

- fast, convenient online submission

- thorough peer review by experienced researchers in your field

- rapid publication on acceptance

- support for research data, including large and complex data types

- gold Open Access which fosters wider collaboration and increased citations

- maximum visibility for your research: over $100 \mathrm{M}$ website views per year

At BMC, research is always in progress.

Learn more biomedcentral.com/submissions 